Bài báo khoa học

\title{
Úng dụng ảnh viễn thám khảo sát nhiệt độ bề mặt tại thành phố Hồ Chí Minh giai đoạn 2016-2020
}

\author{
Nguyễn Huy Anh ${ }^{*}$, Nguyễn Thùy Đoan Trang ${ }^{1}$, Nguyễn Thị Thảo Nguyên ${ }^{1}$, Trần Văn \\ Trọng ${ }^{1}$, Trần Văn Sơn ${ }^{1}$
}

${ }^{1}$ Trường Đại học Tài nguyên và Môi trường, TP. Hồ Chí Minh; anhnh@hcmunre.edu.vn; doantrang16041998@gmail.com; nttnguyen@hcmunre.edu.vn; tvtrong@hcmunre.edu.vn

*Tác giả liên hệ: anhnh@hcmunre.edu.vn; Tel.: +84-905210473

Ban Biên tập nhận bài: 14/6/2021; Ngày phản biện xong: 9/7/2021; Ngày đăng bài: 25/9/2021

Tóm tắt: Là đô thị lớn và quan trọng của đất nước, TP. Hồ Chí Minh đang chịu sức ép lớn từ quá trình công nghiệp hóa, hiện đại hóa, đô thị hóa. Diện tích đất đô thị, bê tông hóa tăng nhanh, đây là một trong các nguyên nhân làm cho nhiệt độ bề mặt ở thành phố gia tăng. Quá trình đảo nhiệt đô thị diễn ra mạnh, nhiệt độ giảm dần từ vùng trung tâm đô thị ra vùng ven đô. Bài báo giới thiệu kết quả sử dụng ảnh vệ tinh Landsat 8 phân tích biến động nhiệt độ bề mặt TP. Hồ Chí Minh trong giai đoạn 2016-2020. Kết quả nghiên cứu cho thấy vùng có nhiệt độ bề mặt từ $30-40^{\circ} \mathrm{C}$ trong năm 2020 là 354,90 ha tăng 60,56 ha so với năm 2016 , đồng thời vùng có nhiệt độ từ $20-30^{\circ} \mathrm{C}$ trong năm 2020 giảm 800 ha so với năm 2016.

Từ khóa: Landsat 8; Nhiệt độ bề mặt; Biến động nhiệt độ.

\section{1. Đặt vấn đề}

Khí hậu là nhân tố ảnh hưởng trực tiếp đến toàn bộ sự sống trên trái đất. Trong những năm gần đây khí hậu đang có sự thay đổi theo chiều hướng xấu đi đối với các sinh vật sống trên trái đất, kể cả con người, đặc biệt là sự gia tăng nhiệt độ toàn cầu. Có rất nhiều nguyên nhân để giải thích cho vấn đề gia tăng nhiệt độ của một khu vực nói riêng và toàn cầu nói chung. Tuy nhiên, khí hậu nóng lên nguyên nhân chủ yếu bắt nguồn từ khí nhà kính là chủ yếu mà con người là nhân tố trực tiếp tác động đến vấn đề này. Ngoài ra, cũng có một số nguyên nhân khác như hiện tượng El Nino gián tiếp thúc đẩy quá trình nóng lên toàn cầu diễn ra nhanh hơn. Dân số ngày càng tăng nhanh, đô thị hóa, công nghiệp hóa-hiện đại hóa tác động đến lớp phủ thực vật làm cho bề mặt Trái Đất thay đổi một cách nhanh chóng điều này cũng dẫn đến nhiệt độ của khí quyển khu vực đó cũng thay đổi.

Công nghệ viễn thám ngày nay đã và đang tiếp tục phát triển một cách nhanh chóng. Ảnh vệ tinh là lựa chọn hàng đầu để giải quyết các vấn đề về nghiên cứu trong các lĩnh vực quản lý tài nguyên, đánh giá biến động lớp phủ bề mặt, trích xuất dữ liệu một cách nhanh chóng và chính xác. Nhờ đó, việc sử dụng ảnh vệ tinh, đặc biệt là ảnh Landsat ngày càng được ứng dụng rộng rãi trong nhiều lĩnh vực nghiên cứu trong đó có nghiên cứu thay đồi nhiệt độ bề mặt đất. Là đô thị lớn và quan trọng của đất nước, TP. Hồ Chí Minh đang chịu sức ép lớn từ quá trình công nghiệp hóa, hiện đại hóa, đô thị hóa. Diện tích đất đô thị, bê tông hóa tăng nhanh, đây là một trong các nguyên nhân làm cho nhiệt độ bề mặt ở thành phố tăng, quá trình đảo nhiệt đô thị diễn ra mạnh. TP. Hồ Chí Minh có lượng bức xạ dồi dào, số giờ nắng trung bình đạt 160-270 giờ/tháng. Nhiệt độ không khí trung bình (nhiều năm) là $27^{\circ} \mathrm{C}$, 
nhiệt độ cao tuyệt đối 400C, tháng có nhiệt độ trung bình cao nhất là tháng 4 . Trong những năm gần đây nhiệt độ trung bình năm ở thành phố Hồ Chí Minh khá cao là 27,80, năm có nhiệt độ cao nhất là $28,6^{\circ} \mathrm{C}$ (2010) năm có nhiệt độ thấp nhất là 27,00 (1986) [1]. Chính vì vậy việc ứng dụng viễn thám trong nghiên cứu đánh giá biến động nhiệt độ bề mặt TP. Hồ Chí Minh là nhiệm vụ cần thiết. Do điều kiện dữ liệu ảnh Landsat và tốc độ phát triển diện tích không thấm ở khu vực trung tâm lớn nên không gian nghiên cứu được lựa chọn giới hạn ở khu vực trung tâm của thành phố (không bao gồm huyện Cần Giờ và Củ Chi), về nội dung nghiên cứu chỉ giới hạn việc sử dụng ảnh vệ tinh phân tích biến động nhiệt độ bề mặt trong các năm 2016, 2018, 2020.

Trong những năm gần đây, về nghiên cứu ứng dụng viễn thám trong nghiên cứu nhiệt độ bề mặt và mức độ khô hạn thực vật (TVDI) đã đạt được những kết quả nổi bật. Năm 2012, trong công trình "Úng dụng ảnh MODIS theo giõi thay đổi nhiệt độ bề mặt và tình trạng khô hạn đồng bằng sông Cửu Long" [2] nhóm tác giả đã sử dụng dữ liệu ảnh MODIS để tính toán nhiệt độ bề mặt đồng thời hoàn thiện quy trình tình toán chỉ số khô hạn thực vật (TVDI). Về hướng ứng dụng viễn thám trong nghiên cứu đô thị hóa có các công trình như: Ứng dụng viễn thám và GIS theo dõi quá trình đô thị hóa tại thành phố Hồ Chí Minh giai đoạn 19892019 [3], nghiên cứu này sử dụng phương pháp phân loại kết hợp các kênh ảnh sẵn có cùng với ảnh tỉ số và phân loại dựa vào các mặt không thấm được xem là đặc trưng của lớp phủ khu vực đô thị. Sử dụng ảnh Landsat tính toán thay đổi nhiệt độ bề mặt đô thị dựa vào việc chuyển đổi từ giá trị điểm ảnh sang giá trị năng lượng bức xạ phổ kết hợp với chỉ số khác biệt thực vật - NDVI (Normalized Difference vegetation Index) [4]. Trong công trình nghiên cứu "Phân tích các yếu tố ảnh hưởng đến hiện tượng đảo nhiệt đô thị bề mặt tại khu vực đô thi Bangkok, Thái Lan”, nghiên cứu đã sử dụng phương pháp phân tích ảnh viễ̂n thám trong trích xuất nhiệt độ bề mặt từ ảnh hồng ngoại nhiệt trên vệ tinh Landsat, xác định phân bố không gian, độ lớn và các yếu tố chính tác động đến đảo nhiệt đô thị bao gồm: mật độ đô thị, tỉ lệ vùng có nhiệt độ cao, tỉ lệ diện tích thực vật phủ, tỉ lệ diện tích mặt nước, tỉ lệ diện tích bề mặt mát [5], nghiên cứu diễn biến đảo nhiệt đô thị bề mặt khu vực phía bắc TP. Hồ Chí Minh từ các kênh hồng ngoại nhiệt [6]. Sử dụng kênh hồng ngoại nhiệt và chỉ số NDVI từ Landsat để ước tính nhiệt độ bề mặt và xây dựng bản đồ nhiệt độ bề mặt đất thành phố [78]. Ngoài ra, còn nhiều công trình nghiên cứu liên quan đến nhiệt độ bề mặt và hiện tượng đảo nhiệt đô thị ở Việt Nam [9-12].

\section{Dữ liệu và phương pháp nghiên cứu}

\subsection{Giới hạn không gian nghiên cưu}

Giới hạn không gian nghiên cứu được xác định là những quận, huyện ở khu vực trung tâm của thành phố, không bao gồm huyện $\mathrm{Củ} C$ hi và huyện Cần Giờ, giới hạn không gian nghiên cứu trên hình 1 .

\subsection{Dũ liệu}

Dữ liệu trong nghiên cứu là ảnh Landsat 8 (LDCM) khu vực thành phố Hồ Chí Minh bao 22 quận huyện (ngoại trừ huyện Cần Giờ, huyện Củ Chi) được thu thập từ hội khảo sát địa chất Hoa Kỳ tại trang web earthexplorer.usgs.gov [13]. Dữ liệu ảnh Landsat thu thập đã được xử lý ở mức $1 \mathrm{~T}$ (đã cải chính biến dạng do chênh cao địa hình), thu thập vào 3 thời điểm $(28 / 2 / 2016,22 / 4 / 2018,23 / 2 / 2020)$ trong mùa khô (tháng 12 đến tháng 4 năm sau), chất lượng ảnh tốt và ít bị tác động bởi mây (tỷ lệ mây < 1\%), tọa độ UTM-WGS-84 zone 48 North (Bảng 1). 


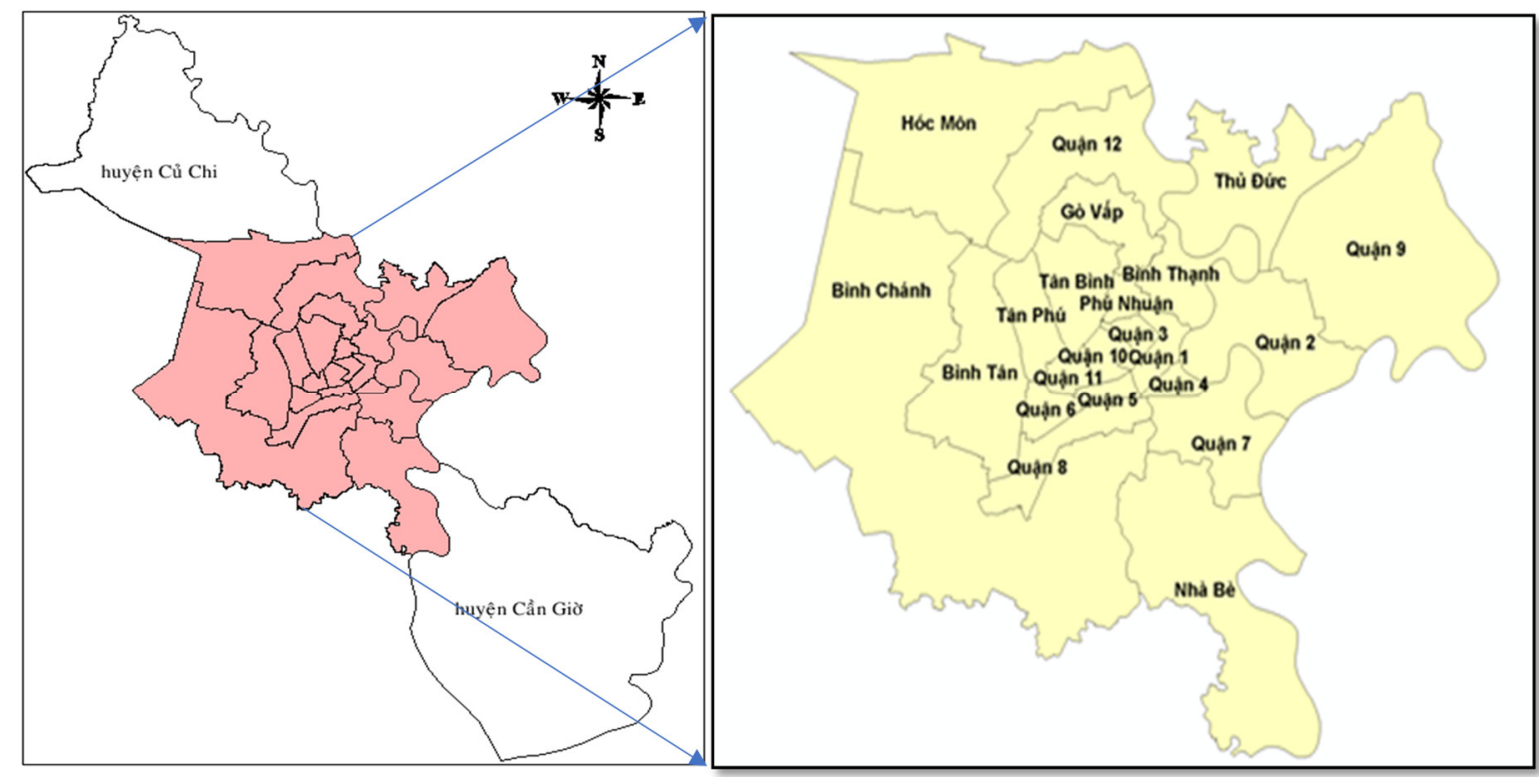

Hình 1. Khu vực nghiên cứu.

Bảng 1. Bảng dữ liệu ảnh vệ tinh landsat 8 được sử dụng trong nghiên cứu này.

\begin{tabular}{cccc}
\hline STT & Loại ảnh & Ngày thu ảnh & Độ phân giải không gian \\
\hline 1 & Landsat 8 & 28 tháng 2 năm 2016 & 30 \\
2 & Landsat 8 & 22 tháng 4 năm 2018 & 30 \\
3 & Landsat 8 & 23 tháng 2 năm 2020 & 30 \\
\hline
\end{tabular}

Landsat 8 (LDCM) mang theo 2 bộ cảm: bộ thu nhận ảnh mặt đất (OLI - Operational Land Imager) và bộ cảm biến hồng ngoại nhiệt (TIRS - Thermal Infrared Sensor). Những bộ cảm này được thiết kế để cải thiện hiệu suất và độ tin cậy cao hơn so với các bộ cảm Landsat thế hệ trước. Landsat 8 thu nhận ảnh với tổng số 11 kênh phổ, bao gồm 9 kênh sóng ngắn và 2 kênh nhiệt sóng dài xem chi tiết ở Bảng 1 . Hai bộ cảm này sẽ cung cấp chi tiết bề mặt Trái Đất theo mùa ở độ phân giải không gian 30 mét (ở các kênh nhìn thấy, cận hồng ngoại, và hồng ngoại sóng ngắn); 100 mét ở kênh nhiệt và 15 mét đối với kênh toàn sắc [14].

Bảng 2. Thông số ảnh vệ tinh Landsat 8 [13].

\begin{tabular}{clcc}
\hline Vệ tinh & \multicolumn{1}{c}{ Kênh/Band } & $\begin{array}{c}\text { Bước sóng } \\
\text { (micrometers) }\end{array}$ & $\begin{array}{c}\text { Độ phân giải } \\
\text { (meters) }\end{array}$ \\
\hline \multirow{2}{*}{$\begin{array}{l}\text { Kênh 1 - Costal aerosol (xanh tím) - quan sát vùng nước } \\
\text { ven bờ và các hạt mịn. }\end{array}$} & $0,433-0,453$ & 30 \\
& Kênh 2 - Blue (xanh lơ) & $0,450-0,515$ & 30 \\
& Kênh 3 - Green (xanh lục) & $0,525-0,600$ & 30 \\
LDCM & Kênh 4 - Red (Đỏ) & $0,630-0,680$ & 30 \\
Landsat8 & Kênh 5 - Near Infrered (NIR) - (Cận hồng ngoại) & $0,845-0,885$ & 30 \\
bộ cảm & Kênh 6 - SWIR1 (Hồng ngoại sóng ngắn 1) & $1,560-1,660$ & 30 \\
OLI và & Kênh 7 - SWIR2 (Hồng ngoại sóng ngắn 2) & $2,100-2,300$ & 30 \\
TIRS & Kênh 8 - Panochromatic (Toàn sắc) & $0,500-0,600$ & 15 \\
& Kênh 9 - Cirrus (Phát hiện mật độ, độ dày mây ti) & $1,360-1,390$ & 30 \\
& Kênh 10 - Thermal Infrered (NIR) 1 (Hồng ngoại nhiệt 1) & $10,3-11,3$ & 100 \\
& Kênh 11 - Thermal Infrered (NIR) 2 (Hồng ngoại nhiệt 2) & $11,5-12,5$ & 100 \\
\hline
\end{tabular}




\subsection{Phưong pháp nghiên cúu}

\subsubsection{Quá trình giải đoán ảnh viễn thám}

Nghiên cứu này sử dụng phương pháp tính toán độ phát xạ từ chỉ số thực vật, từ đó tính nhiệt độ bề mặt dựa vào dữ liệu khu vực nghiên cứu từ ảnh Landsat 8 . Việc sử dụng chỉ số thực vật (NDVI) để xác định độ phát xạ cho toàn bộ khu vực nghiên cứu sẽ cho kết quả nhiệt độ bề mặt khu vực nghiên cứu sát với giá trị nhiệt độ bề mặt thực tế. Việc hiệu chỉnh khí quyển sẽ giúp loại bỏ các hiệu ứng gây nhiễu khí quyển làm ảnh hưởng đến giá trị phản xạ của kênh ảnh làm giá trị nhiệt độ bề mặt khu vực nghiên cứu đáng tin cậy hơn. Quy trình nghiên cứu được thực hiện trên hình 2 .

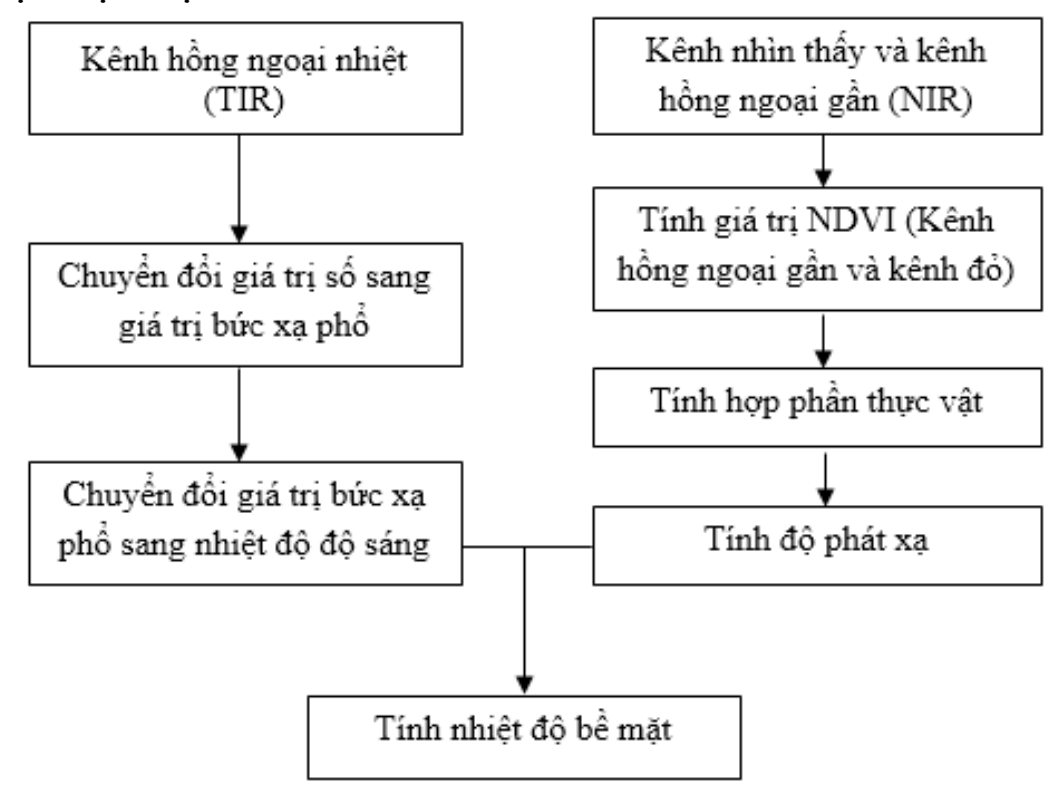

Hình 2. Sơ đồ tiến trình thực hiện.

\subsubsection{Phương pháp tính toán nhiệt độ bề mặt từ ảnh Landsat 8}

Chuyển đổi giá trị số (DN) sang giá trị năng lượng bức xạ phổ: Dữ liệu ảnh vệ tinh Landsat sau khi được thu thập sẽ tiến hành hiệu chỉnh bức xạ chuyển các giá trị số sang giá trị năng lượng phản xạ phổ và các công thức hiệu chỉnh này tùy thuộc vào loại ảnh Landsat. Việc tính toán giá trị phản xạ phổ đối với Landsat 8 không có mối liên hệ với giá trị bức xạ phổ, nên có thể bỏ qua bước tính giá trị bức xạ phổ của từng kênh mà chuyển sang tính trực tiếp theo các công thức sau $[5,14-15]$ :

$$
\mathrm{L}_{\lambda}=\mathrm{M}_{\mathrm{L}} \mathrm{xQ}_{\mathrm{cal}}+\mathrm{A}_{\mathrm{L}}
$$

Trong đó $L_{\lambda}$ là giá trị bức xạ phổ; $\mathrm{ML}$ : hệ số đối với từng kênh ảnh cụ thể (giá trị RADIANCE_MULT_BAND_x trong file metadata ảnh Landsat 8, trong đó $\mathrm{x}$ là kênh ảnh); đối với band 10 của ảnh Landsat 8 thì $\mathrm{ML}=0.0003342$; Qcal: giá trị số của kênh ảnh; AL: hệ số đối với từng kênh ảnh (giá trị RADIANCE_ADD_BAND_x trong file metadata ảnh Landsat 8 , trong đó $x$ là kênh ảnh) đối với band 10 của ảnh Landsat 8 thì $\mathrm{AL}=0,1$.

Tính giá trị nhiệt độ độ sáng: Chuyển đổi giá trị TOA (Top of Atmosphere) bức xạ sang giá trị TOA nhiệt độ độ sáng bằng công thức (2) với hằng số nhiệt được cung cấp trong tệp metadata của ảnh Landsat, đối với band 10 của ảnh Landsat 8 thì $\mathrm{K}_{1}=774.8853 ; \mathrm{K}_{2}=$ $1321.0789[5,9-10]$.

$$
\mathrm{T}_{\mathrm{B}}=\frac{\mathrm{K}_{2}}{\ln \left(\frac{\mathrm{K}_{1}}{\mathrm{~L}}+1\right)}-273.15
$$

Trong đó $\mathrm{T}_{\mathrm{B}}$ là giá trị nhiệt độ độ sáng; $\mathrm{L}$ là giá trị năng lượng bức xạ phổ; $\mathrm{K}_{1}, \mathrm{~K}_{2}$ là hằng số của ảnh hồng ngoại nhiệt được cung cấp trong file metadata ảnh Landsat. 
Tính độ phát xạ: Độ phát xạ của bề mặt tự nhiên khác nhau do các đặc tính của lớp phủ mặt đất khác nhau, như sự khác biệt giữa đồng ruộng, đô thị và đất trống $[5,10,16]$. Độ phát xạ bề mặt $(\varepsilon)$ được tính dựa vào công thức $(3)$ như sau $[5,17]$ :

$$
\begin{gathered}
\varepsilon=m P_{v}+n \\
\text { vớ } i: m=\varepsilon_{v}-\varepsilon_{s}-\left(1-\varepsilon_{s}\right) F \varepsilon_{v} \\
n=\varepsilon_{s}\left(1+\varepsilon_{s}\right) F \varepsilon_{v}
\end{gathered}
$$

Trong đó $\varepsilon \mathrm{V}, \varepsilon s$ lần lượt là độ phát xạ bề mặt của mặt phủ đầy thực vật và đất trống. Các giá trị tham khảo cho $\varepsilon_{\mathrm{V}}$ và $\varepsilon_{\mathrm{s}}$ lần lượt là 0,99 và $0,97[5,13]$. Và $\mathrm{F}$ là chỉ số hình dạng, giả định phân bố hình học là khác nhau và $F=0,55[5,18,19]$. Vì vậy công thức (4) được thể hiện cụ thể bằng công thức (4) như sau:

$$
\varepsilon=0.004 * \mathrm{P}_{v}+0.986
$$

Trong đó $\varepsilon$ : độ phát xạ; Pv: Giá trị hợp phần thực vật (Proportion of Vegetation).

Hợp phần thực vật được tính theo công thức:

$$
P_{v}=\left(\frac{N D V I-N D V I_{\text {min }}}{N D V I_{\text {max }}-N D V I_{\text {min }}}\right) 2
$$

Trong đó Pv là giá trị hợp phần thực vật; Giá trị NDVImin và NDVImax trong khoảng từ -1 đến 1 .

Tính giá trị NDVI: Giá trị hợp phần thực vật $(\mathrm{Pv})$ được tính bằng công thức $(5)$ với chỉ số thực vật (NDVI) bằng công thức (6), và các giá trị cụ thể NDVImin và NDVImax là giá trị nhỏ nhất và lớn nhất của kênh NDVI được thống kê từ kênh ảnh $[5,17]$. NDVI là một thuật toán tiêu chuẩn được thiết kế để ước tính chất lượng thảm thực vật màu xanh lá cây trên mặt đất bằng phép đo phản xạ ở bước sóng màu đỏ và cận hồng ngoại. Để tính được giá trị NDVI áp dụng công thức sau:

$$
\mathrm{NDVI}=\frac{\mathrm{NIR}-\mathrm{Red}}{\mathrm{NIR}+\mathrm{Red}}
$$

Trong đó NDVI là chỉ số thực vật; NIR (Near Infrared) là kênh cận hồng ngoại của ảnh viễn thám Landsat 8 ; Kênh đỏ: Kênh ảnh thuộc vùng ánh sáng nhìn thấy màu đỏ của ảnh Landsat 8.

Ước tính nhiệt độ bề mặt: Nhiệt độ bề mặt đất LST (Ts) là nhiệt độ bức xạ được tính bằng cách sử dụng nhiệt độ độ sáng, bước sóng của bức xạ phát ra, độ phát xạ bề mặt đất theo công thức (7) như sau [3-5, 14]:

$$
\mathrm{Ts}=\frac{\mathrm{T}_{\mathrm{B}}}{1+\left(\lambda \mathrm{x} \frac{\mathrm{T}_{\mathrm{B}}}{\rho}\right) \times \operatorname{Ln}(\varepsilon)}
$$

Trong đó Ts là nhiệt độ bề mặt; TB là nhiệt độ độ sáng; $\lambda$ là bước sóng của bức xạ phát ra (đối với kênh cận hồng ngoại của ảnh Landsat 8 thì $\lambda=10.8$ ); $\varepsilon$ là độ phát xạ; giá trị bước sóng của kênh nhiệt phát xạ $\rho=\frac{h . c}{\sigma}\left(\sigma=1,438 \times 10^{-2} \mathrm{MK}\right)$ với $\rho=$ hằng số Bolzmann $=$ $1,38 \times 10^{-23} \mathrm{~J} / \mathrm{K}$; hằng số Planck $\left(6,626 \times 10^{-34} \mathrm{Js}\right)$; và $\mathrm{c}=$ vận tốc ánh sáng $(2,998 \times 108 \mathrm{~m} / \mathrm{s})$ $[5,10,20]$.

\section{Kết quả và thảo luận}

\subsection{Xác định các tham số}

Để tính xác định được nhiệt độ bề mặt LST $\left(\mathrm{T}_{\mathrm{s}}\right)$ khu vực nghiên cứu từ năm 2016 - 2020 đã tính lần lượt các giá trị như: chuyển đổi giá trị số (DN) sang giá trị bức xạ phổ (L); nhiệt độ độ sáng $\left(\mathrm{T}_{\mathrm{b}}\right)$; độ phát xạ bề mặt $(\varepsilon)$; giá trị hợp phần thực vật $\left(\mathrm{P}_{\mathrm{v}}\right)$; chỉ số NDVI theo các công thực từ $(1)-(7)$. Tất cả những giá trị này đều được sử dụng ảnh Landsat 8 , bằng phần 
mềm ArcGIS 10.6 (phiên bản dùng thử) và sử dụng công cụ Raster calculator, kết quả xử lý ảnh và tính toán các chỉ số được trình bày ở hình 3 .

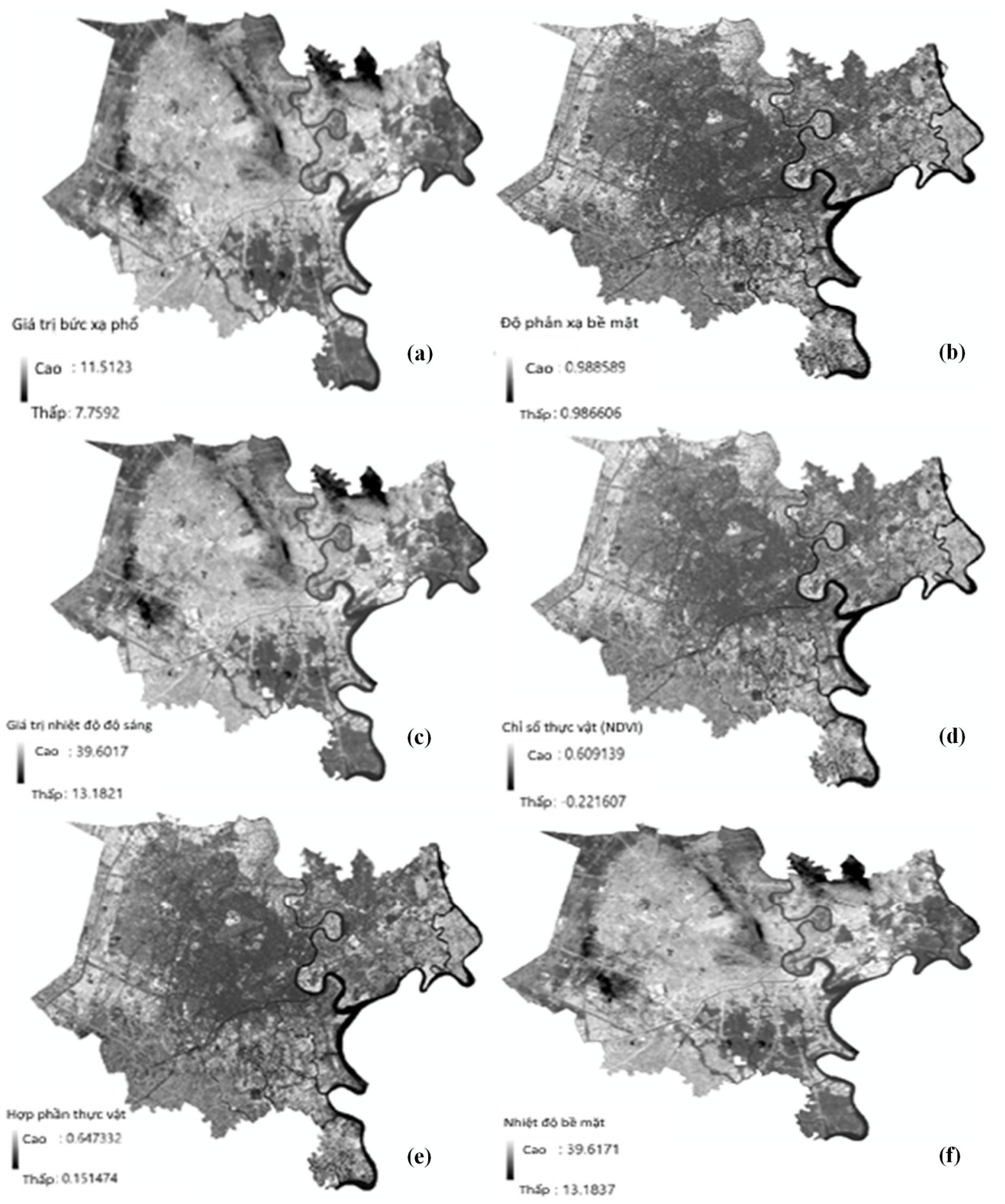

Hình 3. Kết quả tính toán các chỉ số: (a) Giá trị bức xạ phổ (ngày 28/2/2016); (b) Giá trị độ phản xạ bề mặt (ngày 28/2/2016); (c) Giá trị nhiệt độ độ sáng (ngày 28/2/2016); (d) Chỉ số thực vật - NDVI (ngày 28/2/2016); (e) Hợp phần thực vật (ngày 28/2/2016); (f) Nhiệt độ bề mặt (ngày 28/2/2016).

\section{2. Đánh giá sai số}

Sai số là sự sai khác giữa các giá trị thực nghiệm thu được so với giá trị mong muốn. Sai số đánh giá độ chính xác của phương pháp xác định nhiệt độ được xác định từ độ lệch trung bình Bias và sai số $\mathrm{E}(\%)$ giữa các giá trị ước tính từ ảnh vệ tinh với giá trị đo thực tế từ trạm khí tượng theo công thức sau [6]: 


$$
\begin{aligned}
& \text { Bias }=\frac{1}{\mathrm{~N}} \sum_{\mathrm{i}=1}^{\mathrm{N}}\left(\mathrm{T}_{\mathrm{Si}}^{\mathrm{tính}}-\mathrm{T}_{\mathrm{Si}}^{\mathrm{do}}\right) \\
& \mathrm{E}(\%)=\frac{\left|\mathrm{T}_{\mathrm{Si}}^{\mathrm{tính}}-\mathrm{T}_{\mathrm{Si}}^{\mathrm{do}}\right|}{\mathrm{T}_{\mathrm{S} i}^{\mathrm{do}}} \times 100
\end{aligned}
$$

Trong nghiên cứu này do hạn chế về số liệu đo đạc nên sử dụng giá trị nhiệt độ trung bình tại trạm khí tượng Tân Sơn Hòa (quận Tân Bình) để tính toán sai số. Nhiệt độ đo đạc $\mathrm{T}_{(\text {đo) }}$ được lấy từ số liệu nhiệt độ trung bình tháng [1] tương ứng với tháng ảnh landsat được chụp (Bảng 3).

Bảng 3. Sai số tính nhiệt độ qua các thời điểm chụp ảnh.

\begin{tabular}{ccccc}
\hline Thò̀i điểm chụp & T(đo) & T (tính) & $\begin{array}{c}\text { Độ lệch } \\
\text { (Bias) }\end{array}$ & Sai số (\%) \\
\hline 28/2/2016 & 28,3 (tháng 2/2016) & 29,4 & 2,1 & 7,69 \\
22/4/2018 & 30,0 (tháng 4/2018) & 31,3 & 1,3 & 4,34 \\
23/2/2020 & 28,6 (tháng 2/2020) & 29,4 & 2,1 & 7,69 \\
\hline
\end{tabular}

Từ bảng 3 cho thấy độ lệch giữa nhiệt độ tính toán với nhiệt độ đo (giá trị trung bình tháng tại trạm Tân Sơn Hòa) dao động từ $1,3-2,1^{\circ} \mathrm{C}$, tương ứng với sai số từ 4,34-7,69 \%.

Các nghiên cứu trước đây $[6,9]$ đã chứng minh rằng sai số xác định nhiệt độ từ ảnh vệ tinh trong khoảng từ $0,5-2^{\circ} \mathrm{C}$ khi có hiệu chỉnh khí quyển đầy đủ và tùy thuộc vào các phương pháp tính toán khác nhau [6,9]. [9] với sự thiết lập 10 điểm tự quan trắc đã đánh giá sai số cho phương pháp xác định nhiệt độ từ ảnh vệ tinh là $\pm 1,95^{\circ} \mathrm{C}$. Vì vậy, giá trị sai số được tính toán trong bảng 3 là có thể chấp nhận được, phương pháp xác định nhiệt bề mặt từ vệ tinh là đáng tin cậy, có thể dùng hỗ trợ cho các bài toán môi trường và biến đổi khí hậu, trong điều kiện lưới trạm đo mặt đất còn thiếu.

\subsection{Nhiệt độ bề mặt}

Từ kết quả phân tích ảnh viễn thám đã xác định được diện tích và phân bố nhiệt độ bề mặt tại TP. Hồ Chí Minh vào các thời điểm 28/2/2016, 22/4/2018, 23/2/2020, thời kỳ tính toán nhiệt độ bề mặt tập trung vào các tháng mùa khô (tháng $2,3,4$ ).

Bảng 4. Diện tích các cấp nhiệt tại TP. Hồ Chí Minh qua các năm.

\begin{tabular}{cccc}
\hline Nhiệt độ & \multicolumn{3}{c}{ Diện tích (ha) } \\
\cline { 2 - 4 } & $\mathbf{2 8 / 0 2 / 2 0 1 6}$ & $\mathbf{2 2 / 0 4 / 2 0 1 8}$ & $\mathbf{2 3 / 0 2 / 2 0 2 0}$ \\
\hline$<20$ & 0,00 & 1769,4 & 7,47 \\
$20-25$ & $18.091,71$ & $18.044,95$ & $6.025,14$ \\
$25-30$ & $70.955,55$ & $59.238,46$ & $54.102,06$ \\
$30-35$ & $6.580,08$ & $16.557,93$ & $35.319,78$ \\
$35-40$ & 31,95 & 48,55 & 170,28 \\
$>40$ & 0,00 & 0,00 & 34,29 \\
\hline
\end{tabular}

Từ bảng 4 và hình 5 trình bày nhiệt độ các tháng mùa khô tại TP. Hồ Chí Minh qua các năm từ 2016, 2018, 2020. Kết quả cho thấy vào mùa khô (tháng 2, 3,4) với mức nhiệt độ trên $40^{\circ} \mathrm{C}$ có chiều hướng tăng dần, các năm 2016, 2018 kết quả phân tích ảnh chưa xuất hiện, tuy nhiên đến năm 2020 thì mức nhiệt này đã xuất hiện có diện tích 34,29 ha. Ngược lại vùng có nhiệt độ từ $20-25^{\circ} \mathrm{C}$ có chiều hướng giảm, theo đó năm 2016 có diện tích là 18.091,71 ha, 2018 diện tích là 18.044,95 ha và đến năm 2020 diện tích là $6.025,14$ ha. Như vậy, có thể thấy mức nhiệt cao (từ 30-40 ) có xu thế tăng dần, năm 2016 diện tích là 6.612,03 ha đến năm 2020 tăng lên là 35.524,35 ha. Khu vực phân bố chủ yếu ở các quận trung tâm như Phú Nhuận, Tân Bình, quận $10,6,3,11$. Mức nhiệt trung bình và thấp $20-30^{\circ} \mathrm{C}$ có xu thế giảm dần, năm 2016 là 89.047,26 ha đến năm 2020 giảm còn $60.172,20$ ha phân bố ở 
những quận vùng ven có tốc độ đô thị hóa chậm hơn vùng trung tâm như huyện Nhà bè, Bình Chánh, quận 12, TP. Thủ Đức (quận 9 và quận Thủ Đức cũ).
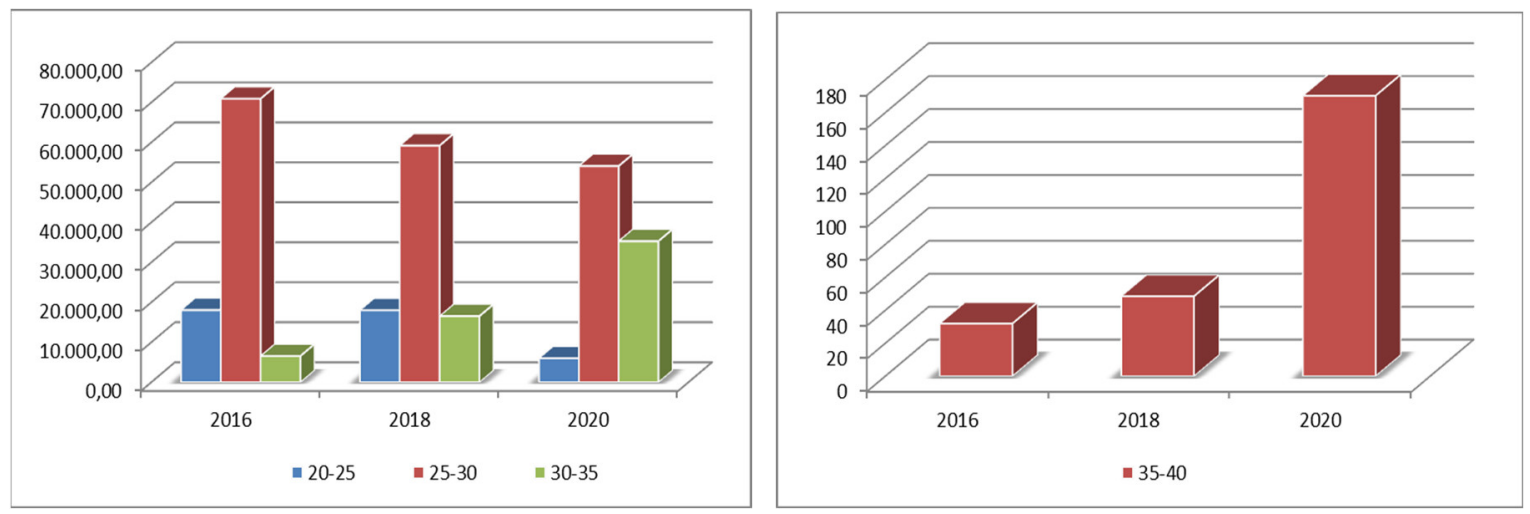

Hình 4. Biến động nhiệt độ theo các năm.

Kết quả tính chỉ số thực vật - NDVI ngày 28/02/2016 (hình 5) và ngày 23/02/2020 (hình 6) cho thấy, chỉ số NDVI có giá trị thấp nhất (vùng màu đỏ) tập trung chủ yếu là các đối tượng các thủy hệ. Theo đó tại khu vực có giá trị NDVI thấp nhất là khu vực mặt nước như sông Sài Gòn, hệ thống kênh, rạch trên địa bàn thành phố. Khu vực dân cư, các tòa nhà, các công trình xây dựng ở trung tâm thành phố hoặc đất trống, đất ruộng khô thì giá trị NDVI ở vào mức thấp đến trung bình thấp. Các khu vực có cây bụi, công viên cây xanh, rừng trồng là nơi có giá trị NDVI từ trung bình cao đến cao.

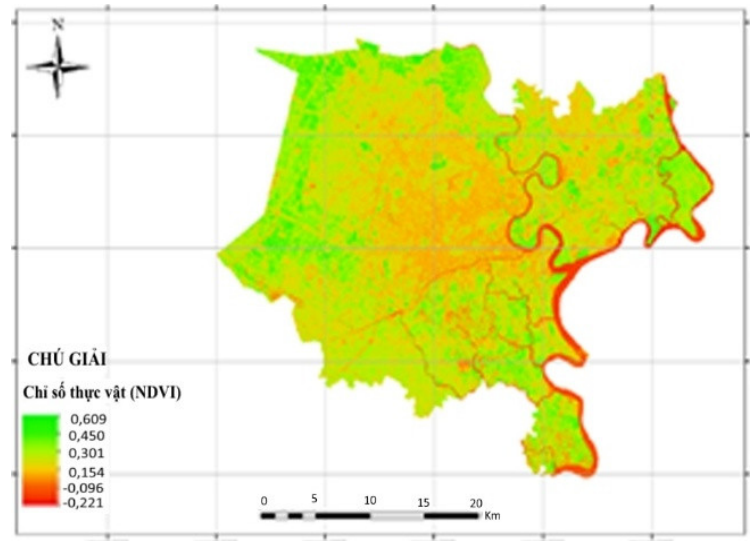

Hình 5. Giá trị NDVI ngày 28/2/2016.

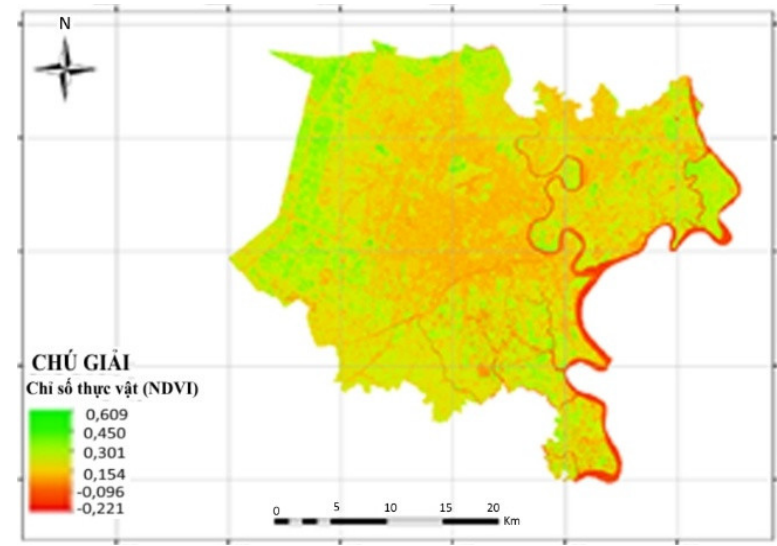

Hình 6. Giá trị NDVI ngày 23/2/2020.

Từ kết quả tính toán NDVI (hình 5,6 ) cho thấy thảm thực vật khu vực nghiên cứu suy giảm rõ rệt trong giai đoạn 2016-2020, nhất là các khu vực các huyện Hóc Môn, Bình Chánh, Nhà Bè và $T P$. Thủ Đức (quận 9 và quận Thủ Đức cũ). Nguyên nhân là do từ năm 20162020 quá trình công nghiệp hóa, đô thị hóa diễn ra mạnh ở các huyện, quận vùng ven, diện tích thảm thực vật bị chuyển đổi sang đất khu dân cư, đất các công trình xây dựng.

Từ kết quả nghiên cứu cho thấy năm 2016 vùng nhiệt độ cao $\left(30-40^{\circ} \mathrm{C}\right)$ có diện tích 6.612,03 ha vùng có nhiệt độ từ $20-30^{\circ} \mathrm{C}$ có diện tích $89.047,26$ ha, tương tự năm 2018 vùng có nhiệt độ $\left(30-40^{\circ} \mathrm{C}\right)$ có diện tích $16.606,48$ ha vùng có nhiệt độ từ $20-30^{\circ} \mathrm{C}$ có diện tích $79.052,81$ ha và năm 2020 vùng có nhiệt độ $\left(30-40^{\circ} \mathrm{C}\right)$ có diện tích $35.524,35$ ha vùng có nhiệt độ từ $20-30^{\circ} \mathrm{C}$ có diện tích $60.134,67.052,81$ ha. 

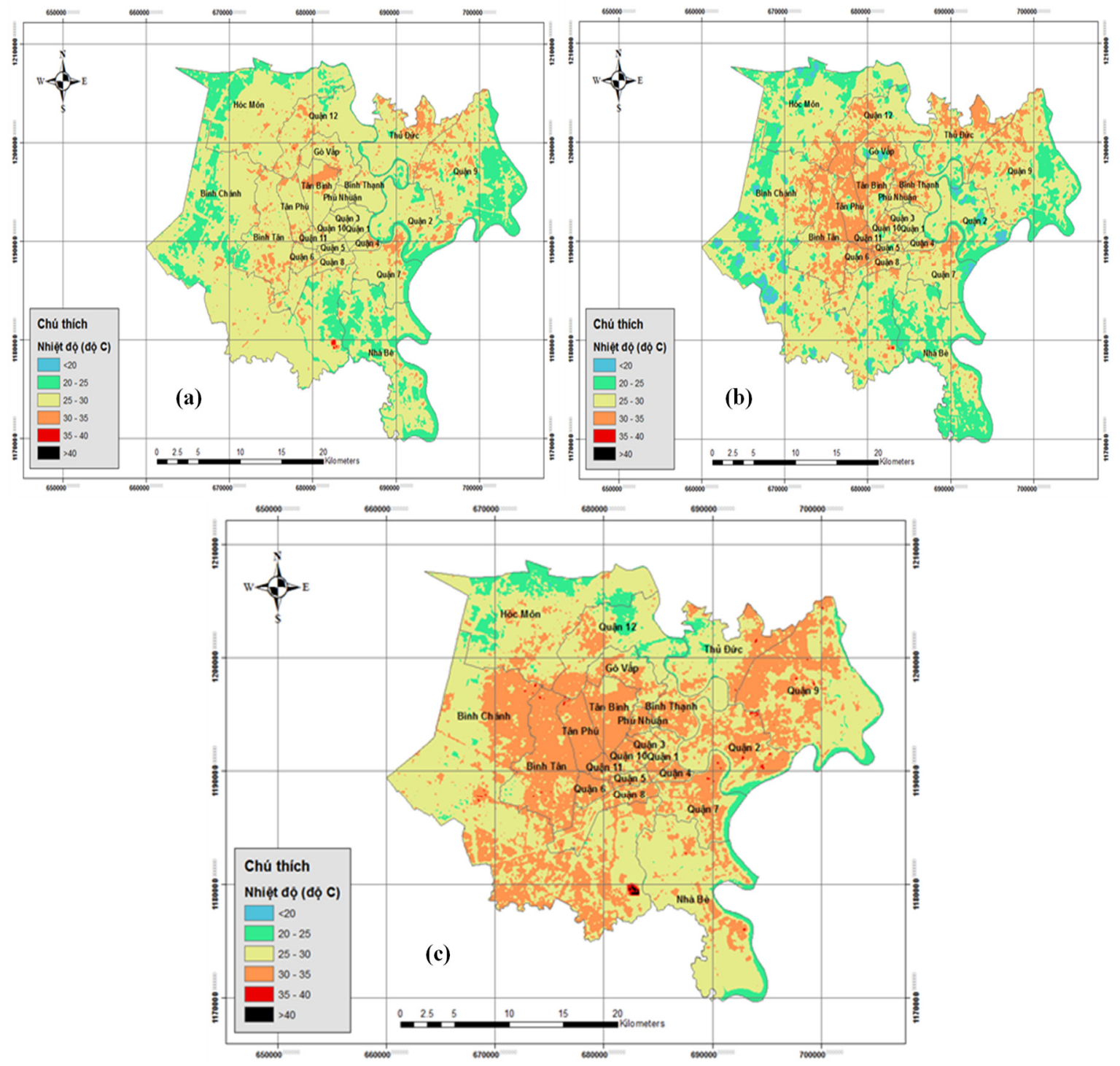

Hình 7. Nhiệt độ bề mặt TP. Hồ Chí Minh giai đoạn 2016-2020: (a) Nhiệt độ ngày 28/2/2016; (b) Nhiệt độ ngày 22/4/2018; (c) Nhiệt độ ngày 23/2/2020.

\section{Kết luận}

Nghiên cứu đã thực hiện được quy trình sử dụng ảnh Landsat để khảo sát nhiệt độ bề mặt thông qua phương pháp xác định nhiệt độ bề mặt bằng cách tính hệ số phát xạ áp dụng chỉ số thực vật NDVI. Phương pháp này có ưu điểm là tính ra giá trị hệ số phát xạ chính xác trên từng điểm ảnh, do đó mức độ chi tiết và chính xác của các bản đồ nhiệt độ bề mặt khu vực nghiên cứu có độ chính xác cao.

Kết quả nghiên cứu cho thấy nhiệt độ độ bề mặt tại khu vực trung tâm TP. Hồ Chí Minh liên tục biến động qua các năm. Đồng thời nhiệt bề mặt của khu vực nghiên cứu chịu sự tác động bởi các yếu tố năng lượng nhận được từ mặt trời, lớp phủ thực vật, hoạt động của con người.

Đóng góp của tác giả: Xây dựng ý tưởng nghiên cứu: N.H.A., N.T.Đ.T.; Lựa chọn phương pháp nghiên cứu: N.H.A., N.T.Đ.T.; Xử lý số liệu: N.T.Đ.T., N.T.T.N., T.V.T. Viết bản thảo bài báo: N.H.A., N.T.Đ.T., T.V.T., T.V.S.; Chỉnh sửa bài báo: N.H.A., N.T.T.N.

Lời cam đoan: Tập thể tác giả cam đoan bài báo này là công trình nghiên cứu của tập thể tác giả, chưa được công bố ở đâu, không sao chép từ những nghiên cứu trước đây; không có sự tranh chấp lợi ích trong nhóm tác giả. 


\section{Tài liệu tham khảo}

1. Bảy N.T.; Phùng, N.K. Đặc điểm khí tượng thủy văn thành phố Hồ Chí Minh. NXB Đại học Quốc gia TP. Hồ Chí Minh, 2018.

2. Hương, H.T.T.; Quang, T.C. Úng dụng ảnh modis theo dõi sự thay đổi nhiệt độ bề mặt đất và tình hình khô hạn vùng đồng bằng sông Cửu Long. Tạp chí khoa họ Đại học Cần Tho 2012, 24a, 49-59.

3. Hạo, L.V.; Mi, L.T.P. Ứng dụng viễn thám và GIS theo dõi quá trình đô thị hóa tại thành phố Hồ Chí Minh giai đoạn 1989-2019. Tạp chí Khí tuợng Thủy văn 2020, $720,48-59$.

4. Thuận, N.Đ.; Vân, P.V. Úng dụng công nghệ viễn thám và hệ thống thông tin địa lý nghiên cứu thay đổi nhiệt độ bề mặt 12 quận nội thành, thành phố Hà Nội giai đoạn 2005-2015. Tạp chí Khoa học Nông nghiẹp Việt Nam 2016, 8(14), 1319-1330.

5. Cần, N.T.; Diệp, N.T.H.; Sanwit, I.; Pariwate V.; Minh, V.Q. Phân tích yếu tố ảnh hưởng hiện tượng đảo nhiệt đô thị bề mặt tại khu vực đô thị Bangkok, Thái Lan. Tạp chí khoa học Đại học Quốc gia Hà Nội, chuyên san Khoa học Trái đất và Môi truờng 2019, 1(35), 53-62.

6. Vân, T.T.; Bảo H.D.X.; Đinh Thị Kim Phượng Đ.T.K.; Mai N.T.T; Nhung Đ.T.M. Đặc điểm môi trường nhiệt và diễn biến đảo nhiệt đô thị bề mặt khu vực bắc thành phố Hồ Chí Minh. Tạp chí Khoa học Đại hoc Cần Tho 2017, 49(A), 11-20.

7. Tuyết, N.H.A.; Thân, N.H. Úng dụng viễn thám đánh giá biến động nhiệt độ bề mặt huyện dầu tiếng tỉnh Bình Dương trong bối cảnh biến đổi khí hậu giai đoạn 2004 2019. Kỷ yếu hội nghị Nghiên cứu khoa học trong "Khoa học trái đất và Môi trường" 2019, 357-360. https://doi.org/10.15625/vap.2019.000154.

8. Hùng, N.V.; Hòa, N.H.; Nghĩa, N.H. Sử dụng ảnh landsat xây dựng bản đồ nhiệt độ bề mặt đất khu vực thành phố Sơn La giai đoạn 2015-2019. Tạp chí Khoa học và công nghệ Lâm nghiệp 2019, 6, 77-87.

9. Vân, T.T.; Lan, H.T.; Trung, L.V. Nghiên cứu thay đổi nhiệt độ bề mặt đô thị dưới tác động của quá trình đô thị hóa ở Thành phố Hồ Chí Minh bằng phương pháp viễn thám. Tạp chí Các Khoa học về Trái đất 2011, 33(3), 347-359.

10. Hùng, T.L. Nghiên cứu sự phân bố nhiệt độ bề mặt bằng dữ liệu ảnh đa phổ Landsat. Tạp chí các Khoa hoc về Trái đất 2014, 36, 82-89.

11. Quang, L.Đ. Sự hình thành đảo nhiệt ở nội thành thành phố Hà Nội. Tạp chi Khi tương Thủy văn 2005, 530, 44-46.

12. Anh, L.V.; Anh, T.T. Nghiên cứu nhiệt độ bề mặt đất sử dụng phương pháp tính toán độ phát xạ từ chỉ số thực vật. Tạp chí Các Khoa học về Trái Đất 2014, 36(2), 184192.

13. Hội khảo sát địa chất Hoa Kỳ. Online avaliable: http://earthexplorer.usgs.gov.

14. Department of the Interior U.S. Geological Survey. Landsat 8 Data User's, Handbook, USA, 2016.

15. LANDSAT Conversion to Radiance, Reflectance and At-Satellite Brightness Temperature (NASA).

16. Van De Griend, A.A.; Owe, M. On the relationship between thermal emissivity and the normalized difference vegetation index for natural surfaces. Int. J. Remote Sens. 1993, 14, 1119-1131. https://doi.org/10.1080/01431169308904400.

17. Carlson, T.C.; Ripley, D.A. On the relationship between NDVI, fractional vegetation cover, and leaf area index. Remote Sens. Environ. 1997, 62, 241-252. https://doi.org/10.1016/S0034-4257(97)00104-1.

18. Sobrino, J.; Jimenez-Munoz, J.C.; Paolini, L. Land surface temperature retrieval from Landsat TM 5. Remote Sens. Environ. 2004, 90, 434-440.

19. Wang, H.; Zhang, Y.; Tsou, J.; Li, Y. Surface Urban Heat Island Analysis of Shanghai (China) Based on the Change of Land Use and Land Cover. Sustainability 
2017, 9(9), 1538. https://doi.org/10.3390/su9091538.

20. Holben, B.N. Characteristics of maximum value composite image from temporal AVHRR data. Int. J. Remote Sens. 1986, 7, 1417-1434.

21. U.S. EPA, Trees and Vegetation, Reducing Urban Heat Islands: Compendium of Strategies, Washington, DC: U.S. Environmental Protection Agency, 2008.

22. U.S. EPA, Green Roofs, Reducing Urban Heat Islands: Compendium of Strategies, Washington, DC: U.S. Environmental Protection Agency, 2008.

\title{
Application of remote sensing of Ho Chi Minh city's surface temparature in period 2016-2020
}

Nguyen Huy Anh ${ }^{*}$, Nguyen Thuy Doan Trang ${ }^{1}$, Nguyen Thi Thao Nguyen ${ }^{1}$, Tran Van Trong ${ }^{1}$, Tran Van Son ${ }^{1}$

${ }^{1}$ University of Natural Resources and Environment, Hochiminh City; anhnh@hcmunre.edu.vn; doantrang16041998@gmail.com; nttnguyen@hcmunre.edu.vn; tvtrong@hcmunre.edu.vn

\begin{abstract}
As a large and important city of the country, Ho Chi Minh City is under great pressure from the process of industrialization, modernization, and urbanization. The rapid escalation of urban land area and concreting is one of the causes for the increase in surface temperature in the city. This paper presents the results of using images of the Landsat 8 satellite to analyse the surface temperature fluctuations in Ho Chi Minh City from 2016 to 2020. Research results indicated that the area with a surface temperature of $30-40^{\circ}$ Celsius in 2020 was 354.90 ha, an increase of 60.56 ha compared to 2016, while the area with a temperature of $20-30^{\circ}$ Celsius in 2020 decreased by 800 ha compared to 2016 .
\end{abstract}

Keywords: Landsat 8; Surface temperature; Temperature change. 